\title{
ENHANCING CULTURAL INTELLIGENCE AND DIGITAL LITERACY IN ACCOUNTING EDUCATION: INSIGHTS FROM A UNIVERSITY'S GLOBAL STUDENT Consulting Programme
}

\author{
Clarence Goh, Yuanto Kusnadi, Gary Pan and Poh Sun Seow
}

School of Accountancy, Singapore Management University, Singapore

\begin{abstract}
Recent literature has advocated for the use of project based learning to engage students in active learning. This study examines how students' learning is enhanced through an overseas project-based learning (PBL) programme at a Singapore University (UNIS), called the UNIS-XO pedagogy. Specifically, this study provides a framework through which students, faculty members, and industry partner can collaborate through consulting programs with the aim to provide feasible recommendations to the clients. Our findings suggest that an experiential PBL with an overseas client is an important learning experience through which students can strengthen their digital literacy as well as cross-cultural competency to make them more futureready for their work.
\end{abstract}

\section{KEYWORDS}

Cultural Intelligence, Digital Literacy, Project Based Learning, Partnership Management

\section{INTRODUCTION}

According to a recent McKinsey \& Company Global Survey of executives, the COVID-19 pandemic has accelerated companies' digital transformation efforts in the way they do business (McKinsey \& Company, 2021). Particularly, the focus of transformation has been on digitalization of customer and supply-chain interactions and the significant increase of digitally enabled products. The survey results have also confirmed the rapid shift toward interacting with customers through digital channels, as these online customers are no longer based only locally but from countries around the world. To stay competitive in this new business environment requires new strategies and practices. As such, there is a pressing need for business executives to adopt a global mindset and enhance their level of digital literacy, as cultural intelligence and digital capability are critical components of new online business model.

To date, digital transformation has brought broad-scale institutional change in many industries, including retail, transportation, accommodation, finance, legal - and accounting is no exception (Pan \& Seow, 2016). Accounting is making a great change of the role it plays in the organization and the function it currently performs. Many manual, routine-based accounting tasks of the past are now increasingly undertaken by automation. In particular, Bhimani \& Willcocks (2014) highlight that the accounting function may drive productivity through automation of processes which in turn, brings about increased efficiency, improved decision-making, and an enhanced control environment. 
While automation is altering the work of accountants, however, it is believed accountants will continue to have a central role to play in most companies (Guthrie \& Parker, 2016). For example, accountants are required to play a data assurance role, offering opinion on whether data are valid, accurate and complete (Kruskopf et al., 2020). Furthermore, with an in-depth knowledge and understanding of customer behaviour, business operation and financial performance, accountants are well placed to offer insights that allow business executives to make effective data-driven decisions (Goh et al., 2019).

With rapid transformation in the accountancy sector, it is therefore not difficult to understand why there is a growing demand for advanced digital knowledge and adequate global exposure for accounting professionals. This calls for an urgent injection of digital knowledge and cultural intelligence in the accounting education that would allow students to navigate a future workplace where use of technology and dealing with global clientele are the norm.

As a consequence, teaching pedagogy at universities has started to evolve from content teaching, to engaging students in active learning, hence focusing on applying and reflecting knowledge, through project-based learning (PBL) (Pan et al., 2019; Seow et al. 2019). An essential feature of $\mathrm{PBL}$ is it is increasingly requiring partnership between universities and companies in devising effective solutions to address complex problems.

Accordingly, this study aims to shed light on students' learning experience of cultural intelligence and digital literacy in a PBL programme at a Singapore University (UNIS). We aim to summarize and highlight students' major takeaways from the programme, and the essentials of partnership management in our study.

The following section provides relevant literature review on the importance of digital literacy and cultural intelligence in accounting education as well as the important role played by PBL. This is followed by description of our research methodology and case studies. Following the case description, we present our findings. The paper concludes with implications for education.

\section{LiterATURE REVIEW}

This section reviews the related literatures on digital literacy and cultural intelligence in accounting education as well as project based learning.

\subsection{Digital Literacy and Cultural Intelligence in Accounting Education}

In recent years, many companies have adopted digital technologies to transform their business operations to meet the needs of dynamic business environment and evolving consumer preferences. These digital technologies include Industrial internet of things (IoT), Big data analytics (DA), Artificial intelligence (AI) and others. What these companies are undergoing is the phenomenon of digital transformation. The impact on companies adopting digital transformation would usually revolve around issues such as requiring new skill set and competences, implementing new tools and applications, revamping organisational settings, and redesigning job scope/retraining to enhance the collaboration between human and machine (Pan \& Lee, 2020).

There is vast scope for gains in innovation and productivity for accounting entity that can capitalize on these rapid technological developments. Increasingly, accountants are expected to know not only how to use basic accounting software to manage data, but also have a solid understanding of critical technological components that drive digital innovation (Goh et al., 2019). For example, technology-related risks and security issues are drawing auditors' attention. Thus, accountants and 
auditors are expected to have a high level of digital knowledge and grounding. In addition, the adoption of smart software and analytics that will enable better and near real-time reporting may allow accountants to transition from retrospective to predictive analysis, and highlighting the interconnectedness of financial and non-financial performance (Pan et al., 2015).

While there is an increasing demand for accountants who are well-versed with digital technologies, however, Amato (2016) reports that there is a lack of professionals who possess relevant technology skills to fill these roles. This gap is apparent not only for experienced professionals but also for entry-level accountants who have accumulated less than three years of work experience (McCann, 2015). One way to address this skill gap is to ensure that young accountants entering the workforce possess skillsets relevant to companies as they seek to capitalize on the potential gains that could be achieved through implementation of new technologies now and in the future.

To ensure that accounting students are equipped with the skillsets needed to exploit developments in technology, various parties including the Association to Advance Collegiate Schools of Business (AACSB International, 2014) and the International Federation of Accountants (Sirois and Savovska, 2017), have appealed to universities to incorporate teaching of relevant technology skills in their programmes. In particular, the AACSB recommends that accounting degree programmes should provide students with relevant data-related skill-sets and knowledge, such as: data creation, data sharing, data analytics, data mining, data reporting, and storage (AACSB International, 2014).

Besides digital literacy, companies are struggling to find enough accountants with the essential skills to function globally. As cultural rules are evolving with the world economy, intercultural business interaction is the new expectation for management accountant. Cross-cultural competency refers to the ability to operate in different cultural settings. This requires not just linguistic skills, but also the ability to be flexible and adaptable to changing contexts (Chiu et al., 2013).

Cultural intelligence (CI) itself is defined as an individual's ability to work effectively in diverse cultural situations. There are four main components in cultural intelligence that are connected to each other (Chua et al., 2012): Metacognitive CI is an individual's ability to analyze mindset, understand, and find solutions for conflicts that arise from cultural diversity. Cognitive CI covers an individual's knowledge and experience of other cultures. Meanwhile, motivational CI is one's desire to adapt in the midst of cultural differences. Lastly, behavioral CI is one's ability to adapt and change attitudes towards people from a variety of cultures. The Cultural Intelligence Center in Michigan proposes four metrics of cultural intelligence (Kenney, 2016): (i) CI Drive - how much do you want to adapt to other cultures? (ii) CI Knowledge - how well do you understand the differences between cultures? (iii) CI Strategy - can you predict and plan for multicultural interactions? (iv) CI Action - can you adapt your words and actions?

According to Stoner and Miller (2010), an accounting curriculum that embeds global awareness and international collaboration may produce accounting graduates that are more well-rounded and able view things from different perspectives and better prepare them for their future career. It is therefore unsurprising student exchange and extensive study programs abroad have become a valuable part of the curriculum for accounting students to hone their cultural intelligence (Helliar, 2013).

\subsection{Project-Based Learning}

PBL is "a systematic teaching method that engages students in learning knowledge and skills through an extended inquiry process structured among complex, authentic questions and carefully designed projects and task" (Markham et al, 2003). 
In addition, PBL should form the "the basis of the curriculum" and not just a "supplementary activity to support learning" (Bell, 2010). Tal et al (2006) further elaborate on the five key features that should be satisfied in a PBL environment: (1) It starts with a problem statement; (2) Students will then initiate discussions and enquiries to perform background research on the problem and then apply relevant knowledge from various disciplines; (3) Collaborations between students, teachers and other members of the community in coming up with solutions for the problem statement; (4) Availability of learning technologies that help to engage students in their inquiry process; and finally, (5) Students produce feasible recommendations to address the problem statement. Overall, PBL is expected to produce positive learning experience for students as highlighted by Gultekin (2005) in terms of critical thinking and problem solving ability.

While many would agree with the importance of incorporating digital literacy and cultural intelligence in accounting curriculum, few research studies have examined students' learning experience in such PBL setting. Accordingly, in this study, we aim to fill the gap in the accounting education literature by shedding light on how universities can facilitate experiential PBL courses. It is also useful to offer some insights into students' lessons learned from such PBL courses.

\section{RESEARCH METHODOLOGY}

We adopted a qualitative research approach with case study design. The case research method enables insights into the process of change as the data are collected over time. In addition, the case methodology guides rather than prescribes activity and may be modified as a result of findings in the field, ie events in context (Yin, 2003).

\subsection{UNIS Study Mission Course}

Since December 2009, UNIS School of Accountancy has been regularly organizing accounting study mission trips to visit companies and organizations in various countries across Asia. The countries visited include: China, Hong Kong, Indonesia, Japan, Laos, Thailand, and Vietnam. The trip usually lasts for at least a week and students will get the chance to interact with the business leaders in those countries.

\subsection{Overseas Experiential Learning Opportunity}

More recently, some of the study mission trips have been converted into UNIS-X Overseas (hereafter denoted as UNIS-XO) courses since August 2018, which offers an overseas experiential learning opportunity for students. One important objective of the UNIS-XO course is to provide students with the learning opportunity to apply the theories and knowledge learnt in classroom into devising practical solutions for real organizations. In addition to visits to companies and organizations, student will also participate in a consultancy project, which is assigned by the project sponsor (typically a company that is based in the country visited).

In addition, one important feature of the UNIS-XO pedagogy is that it is a tripartite collaboration between the faculty member (who will be the instructor of the course), students, and the overseas project sponsor. Through the project collaboration, students will learn how to solve business problems with guidance from the faculty and mentors assigned by the industry partner (i.e. the project sponsor) from problem definition to final presentation - while simultaneously testing their skills in real world settings. 
Overall, a typical UNIS-XO course aimed to fulfil the following learning objectives: (1) understand the foreign country and its political economic development and socio-political diversity, (2) solve real-world problems through a student consultancy project, (3) incorporate experiential and peerlearning, (4) incorporate active mentoring by faculty and project sponsors, and (4) learn how to handle uncertainty in a project.

Therefore, the PBL with overseas clients and exposure to foreign culture are expected to broaden students' cultural intelligence and be more prepared to take on cross-cultural collaboration in the future (Stoner \& Milner, 2010; Chua et al., 2012).

\section{Findings FROM CASE STUdies AND RECOMMENDATIONS}

\subsection{Case Study 1: Study Mission Trip to Laos}

The country of focus in the first case study is Laos and the project sponsor is Company A, a prominent Laotian conglomerate with business interests across a range of industries including fast moving consumer goods (FMCG), automotive, agriculture, and construction. The semester commenced in August 2018 and ended in December 2018, with students first attending six seminars in Singapore and then visiting the Laotian cities of Luang Prabang and Vientiane over a period of eight days. Panel A of Table 1 provides the breakdown of the 29 UNIS undergraduate students enrolled in the course. They were allocated to five project teams and completed three projects.

Table 1: Distribution of Students for the Study Missions Trip

\begin{tabular}{lll}
\hline & Number of students & Percentage $(\%)$ \\
\hline Panel A: Laos trip & & \\
\hline Total number of students & 29 & \\
Male & 16 & $55 \%$ \\
Female & 13 & $45 \%$ \\
Year 2 & 1 & $4 \%$ \\
Year 3 & 12 & $41 \%$ \\
Year 4 and beyond & 16 & $55 \%$ \\
\hline Panel B: Indonesia trip & & \\
\hline Total number of students & 28 & $46 \%$ \\
Male & 13 & $54 \%$ \\
Female & 15 & $7 \%$ \\
Year 2 & 2 & $32 \%$ \\
Year 3 & 9 & $61 \%$ \\
Year 4 and beyond & 17 & \\
\hline
\end{tabular}

While in Laos, students visited six organizations ${ }^{1}$, including Company A, to provide them with the opportunity to interact with a range of local representatives and industry practitioners, further enhancing the cross-cultural learning experience. Together with Company A, faculty from UNIS scoped the following three projects for the students to undertake throughout the semester:

- Balanced scorecard and dashboard: Company A was looking to improve the tools that they use for comparing and tracking of business performance in their automotive business. Accordingly, students were tasked to develop a balanced scorecard that (i) can be universally applied across Automotive sub-units, (ii) make business sense for the company, and (iii) can be practically implemented. They were also tasked to created dashboards to complement the balanced scorecard by allowing Company A to effectively monitor and track business performance. 
- Valuation: Company A was in the early stages of exploring the sale or listing of the branded tires and branded motorcycles sub-units within its automotive business. However, one stumbling block had been the lack of reliable valuations of these sub-units. Accordingly, students were tasked to use relevant accounting information to develop valuation models to provide relevant insights to Company A in its continuing discussions on a possible sale or listing of the various sub-units.

- Setting up of a holding company: As a family business, Company A has issues related to corporate governance. To improve corporate governance, Company A is considering setting up a holding company. Students were tasked to examine the various options available to Company A and to provide recommendations that could inform Company A's decision on a possible restructuring of its business to improve its corporate governance.

The project work commenced in August 2018. They were mentored by UNIS faculty and consulted frequently (virtually) with senior employees of Company A. They concluded their projects by providing Company A with a final presentation and written report of their final prototypes/models/recommendations during their visit to the premises of Company A in December 2018.

\subsection{Case Study 2: Study Mission Trip to Indonesia}

Meanwhile, the second case study revolves around a 'virtual' study mission trip to Indonesia and project collaboration with Bank B, one of the oldest banks in Indonesia. The semester started in January 2020 and it was supposed to culminate in a study trip with a final presentation at the headquarter of Bank B, located in Jakarta, in early May 2020. The breakdown of the 28 undergraduate students enrolled in the course is provided in Panel B of Table 1. Similar to the study mission to Laos, the students were assigned to five projects teams.

The following two projects were scoped for the students to undertake in the semester:

- Penetrating the education industry: Given the large population in Indonesia, Bank B constantly strives to gain more exposure to potential customers in Indonesia and acquire them as its customer base. In the project collaboration with UNIS, the problem statement that was given to the students is to explore initiatives in penetrating the education industry to broaden its clientele base and create customer stickiness.

- Marketing Bank B's corporate internet banking application: To serve non-individual customers' needs in running their businesses, Bank B through its Cash Management Division has developed a corporate internet banking application, named Application V, providing access to customers' accounts anytime anywhere. Customers can both view their accounts and transact through the internet. The main objective of the project is to come up with a marketing plan to increase the usage and penetration rate of Application V.

In the first two weeks of the semester, online Skype calls were made between the students and the mentors assigned by Bank B. The problem statement was clearly explained and defined in the Skype calls and the mentor also addressed some initial questions by the students.

After performing their background research, the students did a mid-term presentation in front of the teaching faculties (which includes the instructor and the adjunct teaching mentor) in Week 9 of the semester. Not only did they obtain "live" feedback from the teaching faculties, they were also to engage the faculties in an interactive discussion which proved to be useful in terms of how they can refine their recommendations. After the presentation, the students continued with the projects for the remaining part of the semester. 
Due to the Covid19 pandemic and border closures, the company visits to Jakarta had to be cancelled and as a result, contingency plans were activated. The company presentations by the business leaders representing the technology, accounting, and start-up sectors were re-arranged and done virtually via teleconferencing platform (WebEx) in the last week of April 2020. More importantly, the faculty and mentors assigned from Bank B also decided for the final presentation to be prerecorded and presented to the senior management team of Bank B online (also via WebEx), at the end of April 2020.

\subsection{Recommendations to Company $A$ in Laos}

Company A's senior management team, including its president, were present to interact with students and listen to their presentations in December 2018.

- Balanced scorecard and dashboard: The two project teams assigned to this project came up with comprehensive balanced scorecards that used weighted measures that Company A could use to track its performance from the financial, customer, internal business, and learning \& growth perspectives. They also created accompanying dashboards using the Microsoft Excel software that would allow Company A to effectively track the performance measures described in the balanced scorecard. Advanced Excel features such as macros and 'what-if' analysis were also incorporated into students' dashboards.

- Valuation: The two project teams that were assigned to this project developed a range of valuation models to value Company A's sub-units. These models were developed using the Microsoft Excel software and employed techniques including the net asset method, the discounted cash flow method, and the comparable companies method. Advanced Excel features such as macros were also incorporated into students' dashboards.

- Setting up of holding company: The project team that was assigned to this project thoroughly researched the topic and came up with a suite of insights and recommendations that were relevant to Company A. Their report and presentation highlighted the key issues related to succession planning that were relevant to a large family run company like Company A, outlined the key benefits of setting up a holding company, and examined the options available to Company A in setting up a holding company (including which jurisdiction to set up the holding company, pros and cons of listing the holding company, etc).

\subsection{Recommendations to Bank $B$ in Indonesia}

The following recommendations were offered by the students doing the two projects with Bank B, when they presented their work to a group of senior management teams of Bank B in late April 2020:

- Penetrating the education industry: One of the proposed recommendations to penetrate the education industry is by integrating seamless adoption of technology from the retailers' perspective. To create stickiness with Bank B's potential customers, the proposed solution by the students aims to resolve the pain points of food vendors in the education industry to achieve efficiency and effectiveness in their business operations. Specifically, the solution is to develop an application that is intended to be a smart retailer-managed application interface and aims to adopt a seamless integrated onboarding for vendors and serve as a one-stop shop for their business needs. An all-in-one dashboard will display the insights of the business's cash flow and projections to provide comprehensive financial visibility for the vendors. There are four main features which tackles the main pain-points of retailers and seek to create 
stickiness by onboarding retailers onto Bank B's ecosystem - inventory management, rental \& loan management, payment management and business insurance.

- Marketing Bank B's corporate internet banking application: To market Application V to SMEs, one of the proposed recommendations was to adopt the 3C strategy - Creation of content to promote the application through YouTube and other social media platform); Collaboration with various YouTubers who are also SME owners to review the application as well as provide tutorials regarding the platform; and Continuation through the setting up of a business association to integrate SME clients into the system and increase stickiness while rolling out new initiatives efficiently.

The senior management team of both Company A and Bank B praised the students for their professionalism and well-executed projects. Overall, they were pleased with the quality of the recommendations and expressed keen interest in implementing UNIS students' respective solutions.

\subsection{Feedback from Client Partners}

Following the completion of the collaboration with UNIS, Company A's president sent a letter of appreciation to the university to record his appreciation of the work that had been done. The letter expressed his gratitude for the "warm partnership and support" extended to his company. It also highlighted that Company A was "impressed by the level of professionalism, the quality work and concerted efforts" that the students had shown. In discussing the benefits that Company A received from sponsoring the projects, Company A's president highlighted that "in today's increasingly competitive market, real-time and objective data is crucial to aid in the business making-decision, and identify and grow talents in the company. The projects embarked on by the UNIS students exactly helped in these matters and point out the areas Company A needs to improve on in order to stay competitive in the market. Moreover, these projects also demonstrate the importance of collaboration, which Company A hopes more companies in Laos can consider to embrace."

The Head of Cash Management of Bank B also thanked the students for the excellent effort put in the project collaborations. He further commented that the mentor managers who had been put in charge of those projects would be summarizing the presentations to the key stakeholders as he believed that some of the recommendations can be adapted to expand Bank B's business. He also hoped that the project collaboration has enriched UNIS's students horizon and mindset, especially when considering banking as a future career possibility.

\subsection{Feedback from Faculty Mentors}

The faculty members who participated in the two courses also shared that they had gained valuable exposure to the Laotian and Indonesian economies and insights into how universities could collaborate to not only enhance the learning of students but also bring benefits to stakeholders involved in the collaboration. Specifically, the faculty involved in the Laos study mission commented, "The UNIS-XO course provided me with a unique opportunity to work with senior executives of one of the most prominent family-run companies in Laos. I gained a first-hand perspective into the unique challenges of doing business in a developing Southeast Asian economy like Laos. Teaching this course also allowed me to gain insights into how academia and industry can work together to bring about unique benefits to various stakeholders."

Meanwhile, the other faculty member in charge of the 'virtual' study mission to Indonesia further highlighted the need for agility in terms of immediate response brought about because of the cancellation of the study trip due to the Covid19 pandemic. The cooperativeness of the project 
sponsor (Bank B) and their support in terms of accommodating online presentations in front of their senior managers were also very much appreciated.

\subsection{Feedback from Students}

End of course feedback evaluation was conducted for students involved in both courses. Questions were asked on a wide range of aspects of the courses: (i) clarity of objectives and expectations, (ii) stimulation of interests in content and project-based learning, (iii) facilitation and mentoring skills, (iv) quality and frequency of feedback, (v) creating opportunities for you to learn from others (partners, guest speakers, peers), (vi) providing you with the opportunities to understand a different culture/way of working overseas, and (vii) enhancing your understanding of the country's economy and industry. Students were then asked to provide their feedback on a Likert-like scale for the above-mentioned questions on a scale of 1 (Extremely Poor) to 7 (Excellent). Table 2 summarizes the mean and the standard deviation of the scores obtained for each question, as compared to the University-average. Panel A presents the findings for the Laos Trip. 23 out of 29 students (79 percent) who participated in the Laos course completed the evaluation survey. Meanwhile, the findings for the Indonesia trip are displayed in Panel B. 24 out of 28 students (86 percent) who were involved in the Indonesia course completed the evaluation survey. As observed in both panels, the mean score for each question is above that of the University-average score, highlighting that students who participated in both courses had benefitted from the experiential PBL with an overseas client partner.

Table 2: End of Course Feedback Evaluation Scores

\begin{tabular}{|c|c|c|c|}
\hline Questions & $\begin{array}{l}\text { Mean } \\
\text { Scores }\end{array}$ & $\begin{array}{l}\text { Std } \\
\text { Dev }\end{array}$ & $\begin{array}{l}\text { University } \\
\text { Average }\end{array}$ \\
\hline \multicolumn{4}{|l|}{ Panel A: Laos trip } \\
\hline Clarity of objectives and expectations & 6.619 & 0.498 & 5.837 \\
\hline Stimulation of interest in content and project-based learning & 6.333 & 0.730 & 5.954 \\
\hline Facilitation and mentoring skills & 6.286 & 0.717 & 5.973 \\
\hline Quality and frequency of feedback & 6.429 & 0.598 & 5.920 \\
\hline $\begin{array}{l}\text { Creating opportunities for you to learn from others (partners, } \\
\text { guest speakers, and peers) }\end{array}$ & 6.619 & 0.498 & 6.041 \\
\hline $\begin{array}{l}\text { Providing you the opportunity to understand a different } \\
\text { culture/way of working overseas }\end{array}$ & 6.810 & 0.402 & 6.697 \\
\hline $\begin{array}{l}\text { Enhancing your understanding of the country's economy and } \\
\text { industries }\end{array}$ & 6.762 & 0.436 & 6.424 \\
\hline \multicolumn{4}{|l|}{ Panel B: Indonesia trip } \\
\hline Clarity of objectives and expectations & 6.318 & 1.086 & 6.026 \\
\hline Stimulation of interest in content and project-based learning & 6.364 & 0.790 & 6.191 \\
\hline Facilitation and mentoring skills & 6.409 & 0.796 & 6.172 \\
\hline Quality and frequency of feedback & 6.500 & 0.673 & 6.085 \\
\hline $\begin{array}{l}\text { Creating opportunities for you to learn from others (partners, } \\
\text { guest speakers, and peers) }\end{array}$ & 6.545 & 0.739 & 6.252 \\
\hline $\begin{array}{l}\text { Providing you the opportunity to understand a different } \\
\text { culture/way of working overseas }\end{array}$ & 6.182 & 0.007 & 5.806 \\
\hline $\begin{array}{l}\text { Enhancing your understanding of the country's economy and } \\
\text { industries }\end{array}$ & 6.136 & 0.008 & 5.811 \\
\hline
\end{tabular}

Other qualitative feedbacks are presented in Table 3. In particular, students acknowledged the relevance and challenges of working on real-world projects, particularly in a foreign country that they were unfamiliar with. The opportunity to work with managers from a different country and to apply the theories learnt into practical applications are other important appealing factors of the 
project collaboration. While the Covid10 pandemic resulted in the cancellation of the Indonesia trip, students still appreciated the chance to understand the banking industry in Indonesia.

Table 3: Qualitative Feedbacks by Students

Feedback \#1 - This ASM gave me the opportunity to immerse myself in a completely different culture. If not for the study mission, I wouldn't have visited Laos and learnt about the people and culture there. Most importantly, I have learnt to be adaptable, especially in situations where I am working with different people, or when I am in a different country.

Feedback \#2 - When working with Company A, we often did not have sufficient information or data that is of sufficient quality and we had to work around that. Furthermore, we had to figure out the direction of our project and our final product by ourselves so I appreciate the independence we were given to challenge ourselves.

Feedback \#3 - In my opinion, this course enables me to not only understand the traditions, culture and working ethics of another country like Indonesia, but also to be exposed to business and accounting concepts which are necessary in analysing the current business products, market and financial capabilities. Additionally, this course also challenged me to bridge the knowledge of what I have to what is required. Furthermore, through this course I have learnt how to structure and format a persuasive recommendation.

Feedback \#4 - Despite not being able to go to Indonesia, I have learnt new information about Indonesia from other students and the professor, as well as the sharing by Indonesians experts. Being able to work with Bank $\mathrm{B}$ helped to increase my understanding of Indonesia banking landscape and gave me a more open-minded view of how business differs across different countries."

Taken as a whole, the survey results and the qualitative feedbacks corroborate Pan \& Seow (2016), Chiu et al. (2013) and Helliar (2013) by identifying the experiential PBL with an overseas client as a means for students to strengthen their digital literacy as well as cross-cultural competency to make them more future-ready for their work, which represents the main contribution of this study.

\subsection{Partnership Management and Benefits of Project Collaboration with University}

Partnership management is a key component to the success of project-based learning, such as that employed in the course (Pan et al., 2021). In particular, both UNIS and the project sponsors (Company A and Bank B) had taken care to manage the partnership in four key aspects.

First, the value proposition of the study mission was clearly established. By participating in the study mission, both students and university faculties were able to learn about the Laotian and Indonesian economy and business environment. Students also enhanced their learning by working on real-world projects. At the same time, the project sponsors were able to benefit from the ideas and recommendations provided by the students through the projects.

Second, both UNIS and the project sponsors were committed to deep collaborations on the projects. Students and faculty from UNIS spent a total of fourteen weeks working on the projects in close collaboration with five senior executives from Company A as well as four senior managers from Bank B. When students made their final presentations to Company A, the full senior management team, including the company's president, was on hand to listen and provide feedback to the students. Likewise, during the final presentation session to Bank B, all the four senior managers as well as the Head of New Digital Ventures of Bank B dialled in and listened to all the four online presentations held over WebEx.

Third, there was extensive knowledge creation and exchange between the UNIS and the industry partners. As part of the projects, students created solutions including balanced scorecards, business 
dashboards, valuation models that were readily adopted and implemented by Company A, Similarly, recommendations on how to penetrate the education industry and increase usage rate of online banking application of Bank B were feasible and can be pursued by Bank B. Students and faculty also benefited from the knowledge gained from the unique opportunity to work with senior executives of one of the most prominent family business in Laos as well as a regional bank based in Jakarta.

Fourth, the partnership was greatly enhanced by the continuous feedback offered by all parties. Early on in the collaboration, the regular feedback and communication between university faculties, Company A, and Bank B was crucial in developing projects that were realistic, relevant, and beneficial to both students and the company. Throughout the collaboration, both Company A and Bank B also offered clear feedback on its expectations of the projects. This provided clear guidance to both the faculty and students on key project deliverables.

\section{CONClusion}

This paper examines students' learning experience of cultural intelligence and digital literacy in a project-based learning course setting. By drawing upon a case study of UNIS, we summarize and highlight students' major takeaways from the course, and the essentials of partnership management in our study. For educators, this study offers useful insights to understanding the roles ought to be played by the teacher and the students so as to ensure an effective PBL course. Our study has also described key features of partnership management in PBL. For any partnership to work, understanding each other's role is important. In particular, the case study has shown university pedagogy may have to evolve with times to satisfy the requirements of employers in the present and the future. It is clear university education plays an important role in equipping and nurturing digital literacy and cultural intelligence within students.

\section{REFERENCES}

[1] AACSB International. (2014). AACSB international accounting accreditation standard A7:Information technology skills and knowledge for accounting graduates: An interpretation. AACSB International Committee on Accreditation Policy. Retrieved from: http://www.aacsb.edu//media/aacsb/publications/white-papers/accounting-accreditation-standard-7.ashx?la=en

[2] Amato, N. (2016). Data Analysis Skills Lacking among Finance Teams. CGMA Magazine. Retrieved from: https://www.cgma.org/magazine/2016/apr/data-analysis-skills-in-finance-201614245.html.

[3] Bell, S. (2010). Project-based Learning for the 21st Century: Skills for the Future. The Clearing House: A Journal of Educational Strategies, Issues and Ideas, 83(2), 39-43.

[4] Bhimani, A. \& Willcocks, L. (2014). Digitisation, 'Big Data' and the Transformation of Accounting Information. Accounting and Business Research, 44(4), 469-490.

[5] Chiu, C., Lonner, W., Matsumoto, D. \& Ward, C. (2013). Cross-Cultural Competence: Theory, Research, and Application. Journal of Cross-Cultural Psychology, 44(6), 843-848.

[6] Chua, R., Morris, M. \& Mor, S. (2012). Collaborating Across Cultures: Cultural Metacognition and Affect-based Trust in Creative Collaboration. Organizational Behavior and Human Decision Processes, 118(2), 116-131.

[7] Goh, C., Pan, G., Seow, P. S., Lee, B. \& Yong, M. (2019). Charting the Future of Accountancy with AI. CPA Australia (Publisher), Singapore.

[8] Gultekin, M. (2005). The Effect Of Project Based Learning on Learning Outcomes in the 5th Grade Social Studies Course in Primary Education. Educational Sciences: Theory and Practice, 5(2), 548-556.

[9] Guthrie, J. \& Parker, L. D. (2016). Whither the Accounting Profession, Accountants and Accounting Researchers? Commentary and Projections. Accounting, Auditing and Accountability Journal, 29(1), $2-10$.

[10] Helliar, C. (2013). The Global Challenge for Accounting Education. Accounting Education, 22(6), 510-521. 
International Journal of Education (IJE) Vol.9, No.2, June 2021

[11] Kenney, A. (2016). The Case for Cultural Intelligence. Financial Management, 1 June, AICPA.

[12] Kruskopf, S., Lobbas, C., Meinander, H., Soderling, K., Martikainen, M. \& Lehner, O. (2020), Digital Accounting and the Human Factor: Theory and Practice. ACRN Journal of Finance and Risk Perspectives, 9(1), 78-89.

[13] Markham, T., Larmer, J. and Ravitz, J. (2003). Project Based Learning Handbook: a Guide to Standards-focused Project Based Learning (2nd Ed.). Novato, CA: Buck Institute for Education.

[14] McCann, D. (2015). Finance and Accounting Skills Gap Vexes CFOs. Cfo.Com. Retrieved from: http://ww2.cfo.com/training/2015/02/you-just-cant-get-good-help-anymore-accounting-skills-gap/

[15] McKinsey \& Company (2021). The Next Normal Arrives: Trends that Will Defimie 2021 - and Beyond. Retrieved from: https:/www.mckinsey.com/featured-insights/leadership/the-next-normalarrives-trends-that-will-define-2021-and-beyond\#

[16] Pan, G., Seow, P. S., Chan, C. \& Lim, C. Y. (2015). Analytics and Cybersecurity: The Shape of Things to Come. CPA Australia, Singapore.

[17] Pan, G. \& Seow, P. S. (2016). Preparing Accounting Graduates for Digital Revolution: a Critical Review of Information Technology Competencies and Skills Development. The Journal of Education for Business, 91(3), 166-175.

[18] Pan, G., Seow, P. S. \& Koh, G. (2019). Examining Learning Transformation in Project-based Learning Process. Journal of International Education in Business, 12(2), 167-180.

[19] Pan, G. \& Lee, B. Leveraging Digital Technology to Transform Accounting Function: Case Study of a SME. International Journal of Accounting and Financial Reporting, 10(2), 2020, pp. 24-38.

[20] Pan, G., Seow, P. S., Shankararaman, V. \& Koh, K. (2021). Essence of Partnership Management in Project-based Learning: Insights from a University's Global Project Programme. Journal of International Education in Business, Forthcoming.

[21] Seow, P. S., Pan, G. \& Koh, G. (2019). Examining an Experiential Learning Approach to Prepare Students for the Volatile, Uncertain, Complex and Ambiguous (VUCA) Work Environment. The International Journal of Management Education, 17(1), 62-76.

[22] Sirois, B. A. \& Savovska, KS. (2017). Audit Data Analytics: Opportunities and Tips,” International Federation of Accountants. Retrieved from: https:/www.ifac.org/global-knowledge-gateway/auditassurance/discussion/audit-data-analytics-opportunities-and-tips

[23] Stoner, G. \& Milner, M. (2010). Embedding Generic Employability Skills in an Accounting Degree: Development and Impediments. Accounting Education, 19(1-2), 123-138.

[24] Tal, T., Krajcik, J. \& Blumenfeld, P. (2006). Urban Schools' Teachers Enacting Project-Based Science. Journal of Research in Science Teaching, 43(7), 722-745.

[25] Yin, R. (2003). Case Study Research: Design and Methods. Sage Publications, Beverly Hills, CA. 3rd ed.

\section{AUTHORS}

Dr. Clarence Goh is Assistant Professor of Accounting (Practice) and Director of the Professional Development at the Singapore Management University. His research interests are in the area of judgment and decision making in financial disclosure, financial information comparability, and data \& analytics in accounting.

Dr. Yuanto Kusnadi is Assistant Professor of Accounting (Education) at the Singapore Management University. His research interests are in corporate governance and innovative pedagogy.

Dr. Gary Pan is Professor of Accounting (Education) at Singapore Management University and the Associate Dean (Undergraduate Admissions and Students Development) of the School of Accountancy at the Singapore Management University. He is also the Academic Director of SMU-X at the Provost Office. His research interests are in information technology enablement of accounting processes and innovative pedagogy..

Dr. Poh Sun Seow is Associate Professor of Accounting (Education) and Associate Dean (Teaching and Curriculum) of the School of Accountancy at Singapore Management University. His research interests are in accounting information systems, behavioural issues in accounting and accounting education. 